\title{
Le-Compte Maneuver in surgical correction of absent pulmonary valve. Does it improve severe bronchial compression?
}

\author{
Bulent Saritas $^{* 1}$, Emre Ozker ${ }^{1}$, Ozlem Sarisoy ${ }^{2}$, Murat Sahin $^{3}$, Ismail Caymaz ${ }^{4}$, Burcak Gumus ${ }^{4}$, Canan Ayabakan ${ }^{2}$ and Sait Aslamaci $^{1}$ \\ ${ }^{1}$ Baskent University Istanbul Hospital, Cardiovascular Surgery, Istanbul, Turkey \\ ${ }^{2}$ Baskent University Istanbul Hospital, Pediatric Cardiology, Istanbul, Turkey \\ ${ }^{3}$ Adiyaman University, Pediatric Cardiology, Adiyaman,Turkey \\ ${ }^{4}$ Baskent University Istanbul Hospital, Interventional Radiology, Istanbul, Turkey
}

\begin{abstract}
Here,we present a case of absent pulmonary valve syndrome operated with Le-Compte maneuver. Although Le-Compte maneuver was performed, endobronshial stent placement was carried out in order to relieve the airway obstruction.
\end{abstract}

\section{Introduction}

Absent pulmonary valve syndrome (APVS) is seen in $3-6 \%$ of patients with tetralogy of Fallot [1]. It differs from the classical form with near absence of the pulmonary valve leaflets and marked dilatation of the main pulmonary trunk and central right and left pulmonary arteries. The enlarged pulmonary arteries usually compress the tracheo-bronchial tree leading to respiratory distress. Anterior and posterior plication or excision of the dilated pulmonary arteries with or without retrosternal suspension are the methods usually used to relieve the bronchial compression ${ }^{2}$. Application of Le-Compte maneuver has been shown to provide substantial relief from obstructive respiratory symptoms in the follow-up of in these patients [2].

Here, a case of absent pulmonary valve syndrome with severe respiratory symptoms is presented. The treatment options to alleviate the airway obstruction are discussed.

\section{Case report}

A 2,5 month-old boy diagnosed of TOF and APVS was intubated because of respiratuary failure and was referred to our clinic for treatment. The echocardiographic evaluation revealed a large perimembraneous-outlet ventricular septal defect (VSD), the aorta overriding the septal defect, and absent pulmonary valve. The pulmonary artery and the branches were massively dilated. The respiratory symptoms were attributed to the airway compression as a result of dilated pulmonary arteries. Thoracic computed tomography (CT) depicted left bronchial obstruction (Figure 1). The diameter of the left main bronchus was $4.7 \mathrm{~mm}$ proximal to the obstruction and it decreased to $2.1 \mathrm{~mm}$ at the level of external compression.

Since the patient had severe respiratory symptoms with significant obstruction of the left main bronchus, excision and plication of the dilated pulmonary arteries along with Le-Compte maneuver was planned to alleviate the bronchial compression.

\section{Surgery}

The VSD was closed with a Dacron patch. Pulmonary artery and the aorta were transected. Dilated pulmonary artery and branches were excised and the plicated. The maneuver of Le-Compte was then performed. A size 12 valved conduit was interposed between right ventricle and main pulmonary artery. The aortic cross clamp and cardiopulmonary bypass times were 102 minutes and 150 minutes respectively.

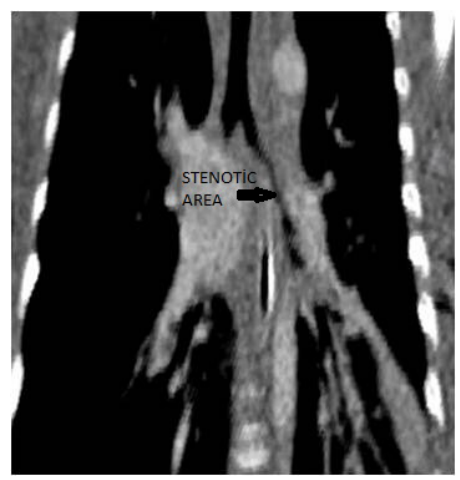

Figure 1. View of preoperative CT angiogram.

Correspondence to: Bulent Saritas, Baskent University Istanbul Hospital, Cardiovascular Surgery, Istanbul, Turkey, E-mail: HYPERLINK “mailto:bsaritas@hotmail.com"bsaritas@hotmail.com

Key words: heart failure, ACE, angiotensin II, ACE2, angiotensin (1-9), angiotensin (1-7), apelin

Received: August 06, 2016; Accepted: August 23, 2016; Published: August 26, 2016 


\section{Postoperative course}

Five hours after the admission to the intensive care unit (ICU), the patient had a sudden drop of systolic blood pressure to $40 \mathrm{~mm}-\mathrm{Hg}$. The echocardiography revealed significant pericardial effusion. Therefore the patient was taken to the operating room. Bleeding from the posterior part of aortic incision was controlled. Thereafter, the postoperative course was uneventful and the patient was extubated shortly after readmission to the ICU. However this was short-lived because of the imminent respiratory acidosis. The chest $\mathrm{x}$-ray showed total atelectasis of the left lung. Fluoroscopic and ultrasonographic evaluation of the left hemi diaphragm ruled out phrenic nerve paralysis. Thoracic CT was repeated to evaluate the bronchial tree postoperatively, which demonstrated the persisting left bronchial obstruction

The details of the site and extent of the obstruction were delineated with bronchography performed by the interventional radiologist (Figure 2), and the obstruction was dilated by deploying a $19 \mathrm{~mm}$ (length) - $5 \mathrm{~mm}$ (width) balloon expandable endovascular stent (Figure 3).

The patient was weaned from the ventilation support gradually and was extubated five days after the stent implantation (postoperative $17^{\text {th }}$ day). He was transferred to the ward and was discharged on the $27^{\text {st }}$ postoperative day. Eighteen months after the operation the patient had not been admitted to hospital for any respiratory problems ever since the discharge.

\section{Discussion}

Absent pulmonary valve syndrome is a rare variant of TOF characterized by rudimentary pulmonary valve leaflets, with centrally deficient cusps and limited mobility. The combination of annular hypolasia and central deficiency of the valvar tissue create the anatomic substrate for combined pulmonary stenosis and insufficiency. This results in aneurismal dilatation of the central pulmonary arteries and obstruction of the tracheobronchial tree. Many of these patients present with severe respiratory insufficiency in infancy and require urgent operative intervention [3].

The mortality for surgical repair of this lesion remains as high as

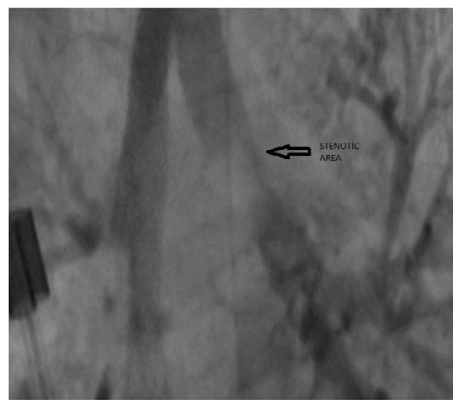

Figure 2. Post-surgery view of bronchography.

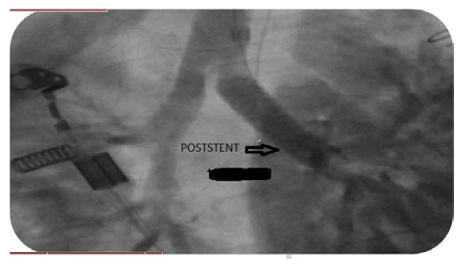

Figure 3. View of post-stent implantation.
$20 \%$ [4]. Most important factor influencing the mortality is the necessity of preoperative mechanical ventilation. The classic repair involves a homograft valve replacement, closure of the VSD, and pulmonary arterioplasty to reduce their size and relieve bronchial compression. Most centers prefer insertion of a valved conduit to restore pulmonary valve competence. Alternatives to this repair include a transannular patch without a homograft/conduit valve, especially if the respiratory symptoms are not severe. In cases where the bronchial compression cannot be ameliorated by pulmonary reduction arterioplasty, the addition of the Le-Compte maneuver to the repair has been shown to provide substantial relief from the bronchial compression [2,3,5]. Tissot et al. [6] have advocated that the Le-Compte maneuver, by transferring the dilated branch pulmonary arteries away from the bronchi, without plication or excision of the vessel may still provide adequate relief of airway obstruction.

In our case, a combination of all these techniques, including the Le-Compte maneuver were used, but were insufficient to eliminate the stenosis in the left main bronchus. This complicated the postoperative course by causing atelectasis in the left lung and prolonging the need for ventilation support. Furthermore adding the Le-Compte maneuver, which is a fairly invasive approach including transection of both great arteries, have led to another complication of cardiac tamponade in our patient.

In cases of APVS, the pulmonary artery dilation is a long-standing issue starting in utero, which causes continuing bronchial malasia even after the operation. In our patient, the constriction of the left main bronchus persisting after the operation was successfully treated with insertion of a balloon expandable stent. Endobronchial stent implantation is a common therapy used for various pathologies in adults. However the lack of appropriate sizes and having no potential of growth limit their use in children [7]. On the other hand, balloon expandable stents have the possibility of balloon re-dilation should the child outgrow its size. Simultaneous surgical correction of the bronchial constriction and the heart defect is possible; however it is a quite invasive approach causing significant morbidity and mortality [8].

Absent pulmonary valve syndrome is not only a congenital heart defect, but also a disease of the tracheobronchial system that has a high propensity to persist after the surgical correction of the heart defect. Regardless of the surgical technique used, the persisting respiratory disorder may complicate the postoperative course and may result in adverse outcomes. Although its main disadvantage is the lack of progressive grow in children, endobronchial stent appication may be an effective option in such cases.

\section{References}

1. Hraska V, Photiadis J, Schindler E, Sinzobahamvya N, Fink C, et al. (2009) novel approach to the repair of tetralogy of Fallot with absent pulmonary valve and the reduction of airway compression by the pulmonary artery. Semin Thorac Cardiovasc Surg Pediatr Card Surg Annu: 59-62

2. Hraska V, Kántorová A, Kunovský P, Haviar D (2002) Intermediate results with correction of tetralogy of Fallot with absent pulmonary valve using a new approach. Eur J Cardiothorac Surg 21: 711-714. [Crossref]

3. Yong MS, Yim D, Brizard CP, Robertson T, Bullock A, et al. (2014) Long-term outcomes of patients with absent pulmonary valve syndrome: 38 years of experience. Ann Thorac Surg 97: 1671-1677. [Crossref]

4. McDonnell BE, Raff GW, Gaynor JW, Rychik J, Godinez RI, et al. (1999) Outcome after repair of tetralogy of Fallot with absent pulmonary valve. Ann Thorac Surg 67: 1391-1395. [Crossref]

5. Nölke L, Azakie A, Anagnostopoulos PV, Alphonso N, Karl TR (2006) The Lecompte 
Saritas B (2016) Le-Compte Maneuver in surgical correction of absent pulmonary valve. Does it improve severe bronchial compression?

maneuver for relief of airway compression in absent pulmonary valve syndrome. Ann Thorac Surg 81: 1802-1807. [Crossref]

6. Tissot C, Aggoun Y, Beghetti M, da Cruz E, Sierra J, Kalangos A (2007) The Lecompte maneuver as an alternative to reduction pulmonary arterioplasty for relief of airway compression in absent pulmonary valve syndrome. Ann Thorac Surg 83: 727
7. Furman RH, Backer CL, Dunham ME, Donaldson J, Mavroudis C, et al. (1999) The use of balloon-expandable metallic stents in the treatment of pediatric tracheomalacia and bronchomalacia. Arch Otolaryngol Head Neck Surg 125: 203-207. [Crossref]

8. Joshi A, Agarwal S, Aggarwal SK, Datt V, Sethi GR, et al. (2013) Single stage repair of tetralogy of fallot associated with left pulmonary artery sling and tracheal stenosis. $J$ Card Surg 28: 595-598. [Crossref]

Copyright: @2016 Saritas B. This is an open-access article distributed under the terms of the Creative Commons Attribution License, which permits unrestricted use, distribution, and reproduction in any medium, provided the original author and source are credited. 